\title{
Historia y futuro de las rentas mínimas en Euskadi
}

\author{
The past and future of minimum income benefits in Euskadi
}

\author{
Iñaki Uribarri Hernández \\ Ezker Sindikalaren Konbergentzia \\ uribarri@esk-sindikatua.org
}

Recibido: $31 / 10 / 2011$

Revisado: 03/11/2011

Aceptado: 28/11/2011

Disponible on line: 15/02/2012

\section{Resumen}

El presente artículo reseña la evolución de la normativa y la política de rentas mínimas en Euskadi para la lucha contra la pobreza. La influencia del modelo implantado en algunos países europeos tiene su reflejo en algunas de estas acciones que pronto se transformarán en estructurales y se integrarán en los presupuestos ordinarios de las administraciones públicas. Asimismo se analizan los ejes de actuación de las diversas plataformas de lucha contra la pobreza y la exclusión social en la región al hilo de la política de rentas mínimas del gobierno autonómico y la importancia atribuida por las mismas a la política institucional, aunque critican el modelo y la gestión de las mismas.

Palabras clave: salario social, rentas mínimas, lucha contra la pobreza, exclusión social, Plataformas de lucha contra la pobreza, Euskadi

\begin{abstract}
This article summarizes the evolution of the regulations and policies of minimum income benefits in the war on poverty in Euskadi. The influence of the model used in some European countries is reflected in some of these actions which will soon become structural changes and will be integrated into the basic Public Administration budgets. In addition, the lines of action of the various platforms in the war on poverty and social exclusion in the region are analyzed in relation to the Autonomous Government's minimum income benefits and the importance given to institutional policy by them, even though the modeling and management of them is critiqued.
\end{abstract}

Keywords: social salary, minimum income benefits, war on poverty, social exclusion, Platforms of the war on poverty, Euskadi.

Referencia normalizada: Uribarri Hernández, I. (2012): «Historia y futuro de las rentas mínimas en Euskadi». Cuadernos de Trabajo Social, 25(1): 75-85.

Sumario: 1. El origen. Surgimiento en frío. 2. 1998 y 2000. Las ocasiones perdidas de mejorar el modelo de rentas mínimas en Euskadi. 3. El movimiento de lucha contra la pobreza en Euskadi. 4. La Ley 18/2008, de 23 de diciembre, para la Garantía de Ingresos y para la Inclusión Social. 5. Los efectos de la crisis y los ataques a la Renta de Garantía de Ingresos. 6. Conclusiones. 7. Referencias bibliográficas.

\section{El origen. Surgimiento en frío}

La política de rentas mínimas del Gobierno vasco surge por una mezcla de casualidad, seguidismo de la moda europea y sensibilidad social de los sujetos que, en aquellos momentos, estaban al frente de los departamentos afectados. La casualidad está en la Encuesta de Pobreza y Desigualdades Sociales realizada en el año 1986. Se trató de una casualidad, según cuentan en los mentideros de la Administración, porque existía un dinero que, sin otro fin mejor, se utilizó para hacer dicha encuesta. Ni había mucha conciencia del fenómeno de pobreza y exclusión que el estudio detectaría (pensemos que, lo normal, es que las administraciones públicas se muevan a golpe de presión social y en este campo la presión no existía; el fenómeno de la pobreza estaba tapado y era absorbido por el colchón de las economías familiares), ni una voluntad previa de poner en marcha actuaciones políticas. 
La moda europea de desarrollar sistemas distintos a los de la Seguridad Social tradicional para combatir la pobreza y la exclusión, se consolida en los años ochenta del siglo pasado, aunque su avanzadilla está en Bélgica en 1977 (Minimex). Su razón de ser se debe a la comprobación de que las pensiones clásicas asociadas al régimen de la Seguridad Social no frenaban la extensión de la pobreza y la exclusión, porque estas realidades habían cambiado con relación al pasado. Ahora aparecían nuevos fenómenos de pobreza y exclusión asociados al paro de larga duración, a las familias monoparentales, al empleo precario, etc.

No solo diversos países europeos van implantando modelos de rentas mínimas garantizadas (Luxemburgo la Renta Mínima de Garantía en 1986, Francia el Ingreso Mínimo de Inserción en 1988), sino que el propio Parlamento Europeo aprueba a finales de 1988, una resolución sobre la lucha contra la pobreza, pronunciándose a favor del establecimiento en todos los estados miembros de una renta mínima garantizada como factor de inserción de los ciudadanos pobres. En esta misma línea, el Comité Económico y Social recomienda que se implante un mínimo social concebido para ser, a la vez, una red de seguridad para las personas en situación de pobreza y un instrumento necesario para la inserción social. La tendencia culmina con la aprobación por la Unión Europea de su Recomendación 92/441, en la que se señala que conviene continuar los esfuerzos y consolidar el acervo de las políticas sociales y adaptarlas al carácter multidimensional de la exclusión social, lo cual implica asociar a las diversas formas necesarias de ayuda inmediata medidas encaminadas a integrar económica y socialmente a las personas afectadas.

En la comunidad autónoma del País Vasco las políticas públicas contra la pobreza nacieron con el Plan integral de lucha contra la pobreza de 1989, cuyo objetivo fundamental era frenar las consecuencias de la pobreza más severa que la crisis económica de los años 1970 y 1980 había arrojado sobre la sociedad vasca. Este plan a su vez formaba parte de otro más ambicioso, llamado Plan extraordinario «Euskadi en la Europa del 93». Como todo en aquella época, la lucha contra la pobreza también debía quedar incardinada en la perspecti- va del Mercado Único Europeo que se debía crear en 1993.

Finalizado el periodo de aplicación del Plan integral de lucha contra la pobreza en 1992, se comprobó que pretender acabar con una pobreza que se había convertido en realidad endémica a través de medidas extraordinarias, concretadas en ayudas económicas de carácter temporal, no tenía sentido. De este modo, las acciones en esta materia se convirtieron en estructurales y se integraron en los presupuestos ordinarios de las administraciones públicas.

A lo largo de más de dos décadas de existencia, el modelo de lucha contra la pobreza no ha cambiado en lo fundamental, en la comunidad autónoma del País Vasco, por más que haya habido modificaciones legislativas y sucesivas leyes: Ley $2 / 1990$, de 3 de mayo del Ingreso Mínimo de Inserción; Ley 12/1998, de 22 de mayo contra la Exclusión Social; Ley 10/2000, de 27 de diciembre de Carta de Derechos Sociales y Ley 18/2008, para la Garantía de Ingresos y la Inclusión Social.

Este modelo de prestaciones contenía tres figuras:

a) Una prestación garantizada como derecho subjetivo (inicialmente se llamó Ingreso Mínimo de Inserción, luego Renta Básica y en la actualidad Renta de Garantía de Ingresos) para cubrir gastos regulares de primera necesidad (manutención. vestido, calzado). Sus principales condicionantes eran: la edad, 23 años; la inexistencia de rentas y el empadronamiento previo de un año (en el caso de los y las jóvenes en un hogar independiente al de su familia).

b) Una prestación subvencional (sometida a la existencia de presupuesto), que siempre se ha llamado Ayudas de Emergencia Social, destinadas a cubrir gastos extraordinarios de las personas sin recursos y que exigía menores condiciones que el Ingreso Mínimo de Inserción-Renta Básica-Renta de Garantía de Ingresos: 18 años de edad, 6 meses de empadronamiento previo en hogar independiente $\mathrm{y}$ carencia de ingresos suficientes. Conviene hacer referencia aquí a la contradicción existente en el diseño de estas prestaciones, originado por motivos de control del gasto. Una persona joven, se podía independizar de su familia con 
18 años, ir a vivir a una vivienda independiente y contar, 6 meses después, con las Ayudas de Emergencia Social para pagar el alquiler correspondiente; sin embargo, hasta llegar a los 23 años no podría tener derecho a la prestación para su manutención.

c) Un derecho/contraprestación a la inserción laboral (antes llamado convenio de inserción y ahora convenio de inclusión).

Una creación en frío y desde arriba - desde las instituciones - sin demanda social que la exigiese (algunos sindicatos y las potentes asambleas de parados y paradas de la década de 1980 defendían entonces la reivindicación del subsidio indefinido para la gente sin empleo), hizo que este nuevo artefacto prestacional tardase un tiempo en ser metabolizado. La gente pobre de nuestra tierra no era proclive a manifestar su pobreza acudiendo a los Servicios Sociales. La pobreza se expresaba clandestinamente y era socorrida entre redes familiares y de amistad, además del concurso de Cáritas. Pero por otro lado había un hecho que siempre había acompañado a las rentas mínimas en Euskadi: la nula voluntad del Gobierno vasco por publicitarlas, por llevar a cabo campañas de difusión dirigidas, sobre todo, a los colectivos que previsiblemente podrían ser sus principales demandantes.

El libro publicado por el Gobierno Vasco en 2009 y titulado 1984-2008, 25 años de estudio de la pobreza en Euskadi, recoge, en su página 293, lo siguiente:

El impacto del sistema vasco de prestaciones en términos de unidades beneficiarias resulta evidente. De 4.885 unidades anuales beneficiarias de la Renta Básica en 1989 se pasa en 1996 a 16.052, una cifra que apenas se mueve en el año 2000, con 16.550 unidades beneficiarias. Sin embargo el incremento registrado, a partir de entonces, resulta extraordinario, aumentando progresivamente la cifra de unidades titulares de la prestación a partir del año 2000. Se alcanza así una cifra de 28.889 en 2004, con una previsión de 38.900 en 2008. En términos relativos respecto al total de unidades familiares en Euskadi, de aproximadamente un 0,76 por cien de unidades beneficiarias de la prestación en 1989 se pasa a cifras cercanas a 2,35 por cien en 1996 y 2000, para aumentar a 3,85 por cien en 2004 y 4,83 por cien en 2008 .

\section{1998 y 2000. Las ocasiones perdidas de mejorar el modelo de rentas mínimas en Euskadi}

En los años 1998 y 2000 hay sendos cambios de la Ley del Ingreso Mínimo de Inserción. La Ley de 2000, a la que me referiré en el punto 3 , fue un cambio defensivo obligado por la tramitación de una Iniciativa Legislativa Popular, que pretendía llevar a cabo una modificación radical de dicho modelo, transformando su filosofía de base sustentada en las rentas mínimas en otro orientado hacia la Renta Básica universal o ciudadana. Todo se quedó en la aprobación de la Ley 10/2000, de 27 de diciembre, de Carta de Derechos Sociales, que lo único positivo que aportó fue una elevada subida de la prestación hasta el 75 por cien del salario mínimo interprofesional, cambiando este nombre por el de Renta Básica y manteniendo íntegramente el articulado de la Ley contra la Exclusión Social de 1998.

Cuando se estaba preparando la que sería la Ley 12/1998, de 22 de mayo contra la Exclusión Social, los análisis efectuados por los técnicos del Gobierno vasco sobre lo que era casi una década de la experiencia del modelo de rentas mínimas garantizadas, resaltaban aspectos mucho más críticos que, sin embargo, luego no tuvieron su traducción en los correspondientes cambios legales. Entre los puntos fuertes que entonces se reseñaban estaban: la escasa permanencia en el sistema (solo una cuarta parte de las personas usuarias lo seguía utilizando pasados 2 años), el bajísimo fraude y la cobertura de toda la gente potencialmente demandante.

En el lote de los puntos débiles aparecían los siguientes: el grado de satisfacción de la gente perceptora del Ingreso Mínimo de Inserción expresaba, por un lado, que les había ayudado a no caer en la pobreza, pero por otro, la baja eficacia económica para satisfacer las necesidades básicas; sumando Ingreso Mínimo de Inserción y Ayudas de Emergencia Social, una tercera parte de los beneficiarios y las beneficiarias decían que nos les llegaba para cubrir las necesidades básicas de manutención y vivienda; la presión presupuestaria sobre las Ayudas de Emergencia Social no había dejado de crecer, lo que se traducía en que como la dotación presupuestaria no acompañaba para nada a la mayor demanda, se registrase un males- 
tar creciente entre la gente perceptora; la política de inserción se consideraba un fracaso. Hasta 1998 solo un 22 por cien de las familias beneficiarias habían llegado a acceder a un convenio. Las razones que se apuntaban eran: escaso grado de desarrollo de los Servicios Sociales, inexistencia de un marco suficientemente elaborado para soportar el trabajo orientado a la consecución de la inserción y dificultades objetivas producto de un mercado de trabajo insuficiente.

De los análisis del personal técnico derivaban propuestas (parte de las cuales llegaron a estar en algunos borradores de la Ley que se manejaron antes del proyecto definitivo) que, en caso de haberse llevado adelante, habrían supuesto un paso positivo aunque sin cambiar de modelo: desagregar las unidades de convivencia individualizando la prestación, aumentar la dotación del Ingreso Mínimo de Inserción y garantizar una mayor cobertura presupuestaria para las Ayudas de Emergencia Social, separar la doble función que juega el convenio de inserción, como derecho y como contraprestación, reforzando el carácter de derecho a la inserción social y laboral. Solo esta última cuestión tuvo parcialmente su acogida legal. Los convenios de inserción dejaron de ser una contraprestación obligada para aquellas personas perceptoras que únicamente manifestaran una carencia de ingresos y no otras que afectaran a su inserción social o laboral.

\section{EI movimiento de lucha contra la pobre- za en Euskadi}

El surgimiento de las plataformas de lucha contra la pobreza y la exclusión social en la comunidad autónoma del País Vasco tiene mucho que ver con la política de rentas mínimas del Gobierno Vasco. Aunque cada una de ellas cuentan con su propia génesis (las hay que se formaron como un agrupamiento para reflexionar y denunciar los problemas de la pobreza y la exclusión en general, las hay que se constituyeron como una reunión de gente afectada por las ayudas sociales, las hay que tienen desde su origen un carácter muy funcional, de oficina de atención a gente solicitante de las prestaciones sociales...), todas pasan a concederle enorme importancia a la política institucional.
Se puede decir que las plataformas tienen en común los siguientes ejes de trabajo (lo que no significa que todas ellas los aborden todos):

a) La denuncia, la reivindicación y el emplazamiento para que cambie la política de las Administraciones Públicas (no solo la del Gobierno Vasco sino también la de la Diputaciones Forales y los Ayuntamientos). Este eje se desarrolla a través de formas diversas (charlas, difusión de escritos, programas de radio, movilizaciones, etc.)

b) La reflexión sobre temas como la Renta Básica, el papel del trabajo en nuestras sociedades, la feminización de la pobreza, etc.

c) La asesoría y el apoyo a personas solicitantes de las prestaciones sociales.

Desde las plataformas la política de rentas mínimas del Gobierno vasco ha sido criticada en dos planos distintos. El primero es el del objetivo con el que nació: para acabar con la pobreza y la exclusión social. Se consideraban lacras a erradicar dentro de nuestras sociedades opulentas. De hecho, el Plan Integral de Lucha contra la Pobreza se concibió a sí mismo como una terapia de choque temporal porque se estimaba factible que, pasados unos años, ya no tendría sentido: se habría terminado con la pobreza.

El Gobierno vasco ha transformado el objetivo original en otro más llevadero: ya no se trata de erradicar la pobreza sino de hacerla soportable, de convivir con ella; para lo cual, la pobreza a combatir es la más severa. Cuando dice que su política ha tenido éxito, a la hora de hacer retroceder la pobreza y la exclusión, se refiere a este estrato de la gente más pobre.

Las plataformas son muy críticas con el modelo de rentas mínimas garantizadas: consideran que introduce tantas condiciones y tantas limitaciones que resulta ineficaz.

- Se limita la edad: ¿qué pasa con la gente pobre de menos de 23 años?

- Se limita la prestación. Si el salario mínimo interprofesional del Estado español ya está por debajo del umbral de pobreza, la Renta de Garantía de Ingresos (88 por cien del salario mínimo interprofesional) no puede sacar de su situación de pobres a las personas que la reciben. 
- Se limita el acceso, a través del sistema de unidades económicas de convivencia independiente. ¿Qué pasa con las mujeres dentro de esas unidades de convivencia? ¿y con el resto de miembros de la unidad familiar a los que habría que considerar como tales y no como partes de un hogar conjunto?

- Se limita el acceso, también, por la exigencia de un año de existencia (en la reforma en marcha va a pasar a tres años) de empadronamiento en un hogar independiente propio. ¿Qué pasa con los jóvenes, mayores de 23 años, que se independizan, en su primer año de vida independiente, si no tienen ingresos?

Hay un segundo plano en el que las plataformas critican el sistema de rentas mínimas de la comunidad autónoma del País Vasco. Es en el plano de la gestión: un sistema de rentas mínimas condicionadas y basado, por lo tanto, en el control de rentas no tiene necesariamente que funcionar como en la comunidad autónoma del País Vasco. ¿Por qué la puerta de entrada al sistema son las trabajadoras sociales que someten a la gente solicitante a entrevistas humillantes, en la mayoría de los casos y no un procedimiento documental similar al del desempleo o al de las pensiones de la Seguridad Social?

El procedimiento establecido, basado en la figura clave de las trabajadoras sociales como puerta de entrada administrativa a la percepción de las prestaciones sociales, solo se justifica desde el punto de vista de la eficacia disuasoria. Y, con ello, el ahorro presupuestario, en la medida que haya personas que, por no pasar este mal trago no soliciten las ayudas a pesar de tener derecho a las mismas. Y en otro sentido, porque la dilación de las citas atrasa en varios meses el cobro de las mismas.

Las plataformas han presentado sus propuestas y reivindicaciones en los dos planos que se han comentando. Su propuesta fuerte es cambiar de modelo, pasar de un modelo de rentas mínimas condicionadas a otro basado en el derecho a una Renta Básica Universal. Pero, mientras madura la conciencia social y se logra la viabilidad política que haga posible implantar una figura de este tipo, se plantean varias reivindicaciones para mejorar las actuales prestaciones sociales: a) En cuanto a la Renta Básica:

- Rebajar la edad a los 18 años.

- Eliminar el empadronamiento previo de un año en hogar independiente.

- Eliminar el carácter de ingreso familiar que todavía tiene, individualizándola completamente.

- Incrementarla hasta el nivel del salario mínimo interprofesional

b) En cuanto a las Ayudas de Emergencia Social:

- Otorgarles el carácter de derecho subjetivo, igual que la Renta Básica.

- Mientras se consigue que sean un derecho subjetivo duplicar su actual dotación presupuestaria para atender la demanda prevista

c) En cuanto a los convenios de inserción:

- Que tengan la consideración estricta de un derecho que activará, cuando quiera, la persona solicitante y que no estará obligada a firmar con la Administración si no le satisface el resultado de la negociación realizada.

d) En cuanto a la tramitación:

- Será mediante procedimiento exclusivamente documental, sin consulta previa con trabajadora social, para la Renta Básica y las Ayudas de Emergencia Social..

- El pago se realizará con carácter retroactivo al momento de presentación de la documentación.

La iniciativa legislativa popular para una Carta de Derechos Sociales es la experiencia de más entidad que se ha registrado en el País Vasco desde el punto de vista de la acción social, en el terreno de la lucha contra la pobreza y la exclusión social. Y también la que con más impacto y eficacia ciudadana difundió la propuesta de Renta Básica, por más que dicha propuesta no coincida plenamente con la figura canónica de la Renta Básica Universal.

La Carta de Derechos Sociales fue una iniciativa legislativa popular, que es una forma de hacer leyes que hay en todos los parlamentos de las comunidades autónomas del Estado español. Consiste en que, mediante una cantidad de firmas determinadas (30.000 en la comunidad autónoma del País Vasco), de electores y electoras debidamente autentificados, se puede proponer una ley a un parlamento y éste parlamento debe tomarla en consideración y tramitarla como una ley ordinaria. 
La iniciativa legislativa popular para una Carta de Derechos Sociales tuvo el siguiente recorrido histórico en la comunidad autónoma del País Vasco. Fue elaborada en el segundo semestre de 1996, presentada a la autorización de la Mesa del Parlamento en diciembre de ese mismo año (la Mesa tiene la potestad de autorizar o denegar la recogida de las firmas que propone la Iniciativa Legislativa Popular) y autorizada en febrero de 1997. La recogida de las firmas se realizó a lo largo de los cuatro meses preceptivos, entre marzo y junio de 1997. Se recogieron 82.053 firmas. En noviembre de 1997, el Parlamento la admitió a trámite y tardó en tramitarla tres años, habiendo por medio de unas elecciones para renovar el Parlamento vasco y un acontecimiento político de tanta trascendencia, como la tregua de ETA de 15 meses de duración (de septiembre de 1998 a finales de 1999). Fue aprobada el 27 de diciembre de 2000, convirtiéndose en la Ley 10/2000. Una ley que casi nada tiene que ver con la iniciativa legislativa popular original, que fue absolutamente descafeinada a través de las enmiendas de todos los grupos políticos (PNV, PSE-EE, PP, EA y UA), salvo de Ezker BatuaIzquierda Unida y Euskal Herritarrok, que la apoyaron firmemente.

El fenómeno de movilización popular que implicó la iniciativa legislativa popular fue muy grande. Sobre todo en la fase de elaboración de la ley y aún más en la de recogida de las firmas. Participaron más de 100 organizaciones del espectro más variado (ONGs, organizaciones de los entornos de la Iglesia católica, sindicatos, movimientos sociales, asociaciones vecinales, etc.). Se recogieron más de 82.000 firmas a través de las formas más diversas, pero con mucho trabajo de ca1le. La presencia en los medios de comunicación fue muy fuerte en el primer semestre de 1997, estancándose posteriormente durante el largo túnel parlamentario que hubo de pasar y activándose al final de 2000, coincidiendo con su aprobación.

La Carta de Derechos Sociales tiene dos partes: en la primera, contenía tres principios orientadores: uno, el restablecimiento de los derechos universales de ciudadanía para todas las personas que tienen cerrado el acceso al mercado de trabajo y que, por ello, carecen de ingresos económicos para llevar una vida dig- na; dos, el reconocimiento efectivo del derecho ciudadano a una parte del producto social en forma de una Renta Básica para quienes demanden empleo y no lo encuentren; y tres, el reparto del tiempo de trabajo entre quienes demanden empleo, en base a los principios universales de solidaridad, igualdad, etc.

Las propuestas concretas de la Carta eran de dos tipos: por un lado, las que tenían que ver con el reparto del empleo. Como la comunidad autónoma del País Vasco no tiene competencias para regular por ley la jornada de trabajo, se proponía, como medida fundamentalmente ejemplar, que regulara la del personal al servicio de la Administración Pública vasca con esa perspectiva de reparto de empleo: la reducción de la jornada de trabajo a 32 horas semanales, el adelanto de la edad de jubilación a los 60 años y la eliminación de las horas extras.

La otra propuesta se refería a la Renta Básica: se establecía el derecho a la misma para todas las personas mayores de edad, inscritas en los diversos servicios de empleo, que estuvieran censadas con un año de antigüedad en cualquier municipio de la comunidad autónoma del País Vasco y que no encontraban empleo. También se incluía a las personas jubiladas, cuyas pensiones no llegaran al nivel del salario mínimo interprofesional. La cuantía de la Renta Básica sería equivalente al salario mínimo interprofesional.

Esta figura de Renta Básica no tiene carácter universal e incondicional, aunque los colectivos a los que se podría aplicar serían muy amplios, puesto que bastaba con el trámite administrativo, para la gente sin ingresos y mayor de edad, de apuntarse a un registro de desempleados y desempleadas. Para la gente pensionista se necesitaba un control de rentas, es decir: demostrar que la pensión era inferior al salario mínimo interprofesional. Además, en todos los casos se exigía un año de empadronamiento y una contraprestación social, que venía obligada por imperativo legal (para que el Parlamento admitiera la iniciativa legislativa popular) y que estaba redactada así: «acuerdo negociado con la Administración, por medio del cual se establecerá la aportación o contrapartida social que deberán realizar en beneficio de la sociedad. Dicha contrapartida será de carácter social y comunitario sin que tenga en ningún caso naturaleza laboral». 
El principal desenfoque de la fórmula de Renta Básica de la iniciativa legislativa popular es - desde mi punto de vista - su subordinación al empleo. Ello era producto del mayor peso que tenían, en el conjunto de las organizaciones promotoras de esta iniciativa, aquellas cuya cultura trabajista estaba muy arraigada («te ganarás el pan con el sudor de tu frente»).

Sin embargo, más importante que este lastre, fue el eco que tuvo la difusión de una idea tan novedosa como era la de la Renta Básica, el hecho de que frente al Ingreso Mínimo de Inserción y las Ayudas de Emergencia Social del Gobierno vasco, que aparecían a la postre como ayudas sociales (no auténticos derechos), la Renta Básica era un derecho ciudadano con mayúsculas y que, además, se fijaba con un nivel equivalente al salario mínimo interprofesional, necesario si se quería combatir la pobreza.

Un éxito indudable de la iniciativa fue sumar a todos los sindicatos y conseguir que, más allá de este acompañamiento de la iniciativa legislativa popular, la reivindicación de la Renta Básica, con el nombre de Salario Social, figurara en la huelga general de mayo de 1999.

La iniciativa legislativa popular tuvo un final poco glorioso en su tramitación parlamentaria. Los grupos políticos dominantes en el Parlamento vasco la enmendaron hasta hacerla irreconocible. De ella, para más desgracia, solo se salvó el nombre que titula la Ley 10/2000 de Carta de Derechos Sociales y, lo que es peor, se modificó el nombre del Ingreso Mínimo de Inserción por el de Renta Básica, de forma que ahora, para no confundir a la gente, los que seguimos defendiendo la Renta Básica Universal e Incondicional tenemos que decir que no es la Renta Básica del Gobierno vasco. También se obtuvo un incremento de su importe hasta el 75 por cien del salario mínimo interprofesional: supuso pasar de un Ingreso Mínimo de Inserción, que estaba en 303,60 euros. a una Renta Básica de 379,36 euros.

Todos los sindicatos vascos tomaron parte en la iniciativa legislativa popular, sobre todo desde el momento de la recogida de las firmas. El sindicato ESK estuvo en el origen de la iniciativa, teniendo un papel muy activo en la fase de diseño organizativo y redacción de la Carta. Los sindicatos ELA y LAB, que se su- maron más tarde, estuvieron presentes en la Comisión que llevó las gestiones con los partidos políticos en la larga etapa de la negociación parlamentaria.

La iniciativa legislativa popular fue, en definitiva, para buena parte de los sindicatos vascos, el momento en el que descubrieron el tema de la Renta Básica y en el que la empezaron a incorporar a sus reflexiones y a sus programas sindicales.

Dentro de los sindicatos vascos, hubo cuatro (ELA, LAB, ESK y STEE-EILAS) cuya actividad en torno al tema de la Renta Básica ha sido bastante relevante hasta el año 2000. Desde entonces, salvo ESK, parecen haber perdido el interés. El momento cumbre de la movilización sindical a favor de la reivindicación del Salario Social (nombre con el que se conoce mayoritariamente en el mundo laboral a la Renta Básica), lo constituyó la huelga general de 21 de mayo de 1999. En aquella huelga general compartió cartel con la reivindicación de las 35 horas, si bien fue esta consigna la más aireada.

\section{La Ley $18 / 2008$, de 23 de diciembre, para la Garantía de Ingresos y para la Inclusión Social}

Me voy a detener ahora, con mayor extensión, en el último cambio legal, la Ley 18/2008, de 23 de diciembre, para la Garantía de Ingresos y para la Inclusión Social. Esta Ley ha tenido un proceso de maduración largo. Hace años que las diversas administraciones concernidas en la aplicación de la Renta Básica, Ayudas de Emergencia Social y convenios de inserción veían necesario corregir problemas que estaban generando tensiones cada vez más graves en la gestión del modelo: Ayudas de Emergencia Social destinadas fundamentalmente al pago de alquileres, dinámica imparable de la demanda de Renta Básica y Ayudas de Emergencia Social, disfuncionalidad de los convenios de inserción, etc. En un principio se pensó en reformar la Ley contra la Exclusión Social de 1998, pero al irse añadiendo modificaciones sucesivas (sobre todo la Renta Básica complemento de pensiones), se optó por llevar a cabo la promulgación de una ley de nueva planta.

Fruto de ese largo proceso de maduración la Ley de Garantía de Ingresos ha pretendido 
resolver todos los problemas que venía detectando desde la aplicación de la Ley de 1998. Esto ha hecho que, en unos casos haya habido, soluciones positivas y en otros soluciones negativas. Lo positivo de la ley consiste en lo siguiente:

a) Que la Renta Básica para la Inclusión y Protección Social llegue, en el caso de la gente pensionista, al 100 por cien del salario mínimo interprofesional. En este aspecto lo único que ha hecho la Ley es recoger algo ya en vigor desde la Ley de Complemento de Pensiones de julio de 2008 .

b) Que la Prestación Complementaria de Vivienda, que se desgaja de la antigua Ayuda de Emergencia Social, como cantidad autónoma destinada al pago de la vivienda, sea considerada un derecho subjetivo igual a la Renta de Garantía de Ingresos.

c) Que se hayan ampliado las unidades convivenciales consideradas independientes, que pueden convivir en una misma vivienda.

d) Que se haya dotado un complemento, aunque sea bastante ridículo en cuanto a su importe $(6,4$ por cien del salario mínimo interprofesional, 46,6 euros en 2009) para las unidades de convivencia monoparentales.

Lo negativo de la Ley tiene su origen en la voluntad de mantener intocables los principios en los que se ha basado la política de rentas mínimas garantizadas en Euskadi desde su origen: el control de las rentas dejado en manos de los Servicios Sociales de base; el sujeto familiar frente al sujeto individual; el doble derecho a un ingreso mínimo y a la inserción, enredados de tal forma que el convenio de inserción (ahora llamado de inclusión), se convierte en una obligación, más que en un derecho; el límite de los 23 años para cobrar la Renta de Garantía de Ingresos; la no consideración de todas las Ayudas de Emergencia Social como derecho subjetivo.

Los seis aspectos más inaceptables de la Ley de Garantía de Ingresos y del Reglamento que la desarrolla, son los siguientes:

a) Limitación a 2 las Rentas de Garantía de Ingresos como máximo que se pueden cobrar en una misma vivienda, aunque existan más unidades de convivencia que cumplan todas las condiciones para ser sujetos del derecho. b) Limitación de los años en que se puede percibir la Renta de Garantía de Ingresos, según circunstancias del tipo de Renta de Garantía de Ingresos y del tipo de las unidades de convivencia que formen parte de una misma vivienda.

c) Tratamiento especialmente lesivo para la gente inmigrante a través del no reconocimiento con carácter general de que la persona inmigrante con cónyuge en su país de origen es una unidad de convivencia individual, así como a través de la exigencia de aportar un certificado, expedido en su país, de que no posee patrimonio inmobiliario.

d) Presión, por la vía de la empleabilidad, para sacar de la Renta de Garantía de Ingresos al máximo de personas. Y, sobre todo, presión, en este mismo sentido (aumento de su empleabilidad, pues ya es gente que está empleada) a los/as perceptores de la Renta Complemento de Ingresos de Trabajo.

e) Que no se haya dado el carácter de derecho subjetivo a todas las Ayudas de Emergencia Social.

f) Que se haya mantenido, con carácter general, en 23 años la edad para ser sujeto de derecho de la Renta de Garantía de Ingresos.

En resumen y reiterando que deben reconocerse las mejoras que la nueva Ley comporta, hay que destacar:

1) Que se ha perdido una ocasión para ir más allá de la matriz tradicional del modelo de rentas mínimas garantizadas.

2) Que la dinámica práctica que la aplicación de esta Ley traerá en poco tiempo, va a resultar regresiva para toda las personas que antes percibían la Renta Básica, salvo las/os pensionistas, incapacitados e irrecuperables para el empleo. Este resumen lo he tomado de una reflexión hecha en noviembre de 2009, con ocasión del IX Simposio de la Renta Básica, celebrado en Bilbao. Dos años después y con las reformas previstas de la Ley, que analizaré en el punto siguiente, resulta bastante evidente que estaba en lo cierto.

\section{Los efectos de la crisis y los ataques a la Renta de Garantía de Ingresos}

La crisis económica ha provocado un fuerte incremento en el número de personas percepto- 
ras (36.817 en marzo de 2009, 51.903 en marzo de 2010 y 53.981 en marzo de 2011) y en el gasto total en Renta de Garantía de Ingresos, Prestación Complementaria de Vivienda y Ayudas de Emergencia Social (233.000.000 euros en 2008; 317.200.000 euros en 2009 y 389.900.000 euros en 2010). La dinámica del gasto en ayudas sociales siempre ha sido creciente, como ya se ha señalado, al margen de los tiempos de crisis. En el 2000 este gasto fue de 91.800.000 euros, en 2004 alcanzó los 160.600.000 euros y en 2007 llegó hasta 216.500.000 euros.

El contexto de la crisis ha creado condiciones inmejorables para, aprovechando la reforma de la actual Ley para la Garantía de Ingresos y la Inclusión Social, dar una vuelta de tuerca a los elementos excluyentes que propiciaba la Ley, centrados de forma especial en determinados colectivos sociales. Esta reforma iba a consistir, inicialmente, en la introducción de meros cambios administrativos que facultaran al Servicio Público Vasco de Empleo LANBIDE a tramitar la Renta Complemento de Ingresos de Trabajo y la Prestación Complementaria de Vivienda, sustituyendo a los servicios sociales de base de los Ayuntamientos y a las Diputaciones. Un acuerdo del Partido Popular y del Partido Socialista de Euskadi-Euskadiko Ezkerra, en la Comisión de la Ponencia que está tramitando las enmiendas para reformar la Ley, el pasado 12 de septiembre, ha decidido imponer 3 años de empadronamiento previo en la comunidad autónoma del País Vasco o 1 año de empadronamiento más 5 de «actividad laboral remunerada», frente al año que hasta ahora se exige para cobrar la Renta de Garantía de Ingresos. Además también han acordado medidas draconianas referidas a la empleabilidad, medidas que van destinadas a excluir de la Renta de Garantía de Ingresos a perceptores y perceptoras que rechacen cualquier primer empleo adecuado (hasta ahora eran tres).

A los anteriores recortes se viene a añadir uno gravísimo de última hora. El proyecto de Presupuestos del Gobierno vasco para 2012 contempla un recorte del 7 por ciento en las cantidades individuales (es derecho subjetivo) de Renta de Garantía de Ingresos, de Prestación Complementaria de Vivienda y en la cantidad total de Ayudas de Emergencia Social. En los veintidós años de existencia de estas prestaciones jamás había ocurrido algo similar. Equivale a retroceder al año 2006 en que la Renta Básica suponía el 82 por cien del salario mínimo interprofesional, frente al 88 por cien actual.

¿Qué efectos van a deparar estos cambios sobre determinados colectivos de personas perceptoras cuando entre en vigor a principios del próximo año?

a) Miles de inmigrantes y de personas jóvenes, que decidan independizarse de sus familias a partir de los 23 años, van a quedar excluidas durante dos años (hasta que cumplan los 3 de empadronamiento previo) de la Renta de Garantía de Ingresos y la Prestación Complementaria de Vivienda.

b) La gestión de la empleabilidad que desarrolle LANBIDE va a tener, en buena medida, un carácter punitivo sobre la gente perceptora de la Renta de Garantía de Ingresos que no sea pensionista. La persecución de la cruzada de la empleabilidad de la consejera Gemma Zabaleta se va a centrar en 16.600 personas $(30,15$ por cien del total de perceptores y perceptoras de la Renta de Garantía de Ingresos) que cobran una Renta de Garantía de Ingresos parcial, como complemento a sus ingresos de trabajo y 19.000 personas $(34,6$ por cien) que perciben la Renta de Garantía de Ingresos total por carecer de cualquier ingreso.

La Consejera Zabaleta está convencida de que la sostenibilidad del sistema de ayudas sociales vascongado, por un lado exige los recortes que está promoviendo junto al Partido Popular, pero, por otro, debe descansar en el empleo de la gente perceptora. El balance de su cruzada de empleabilidad, por mucho que se empeñe en hacer publicidad engañosa, es bien magro. Las ayudas extraordinarias a la contratación de personas desempleadas puestas en marcha a finales de 2009 y que destinaban como mínimo un 30 por cien de plazas a gente de la Renta de Garantía de Ingresos, permitieron crear durante 6 meses 5.612 puestos de trabajo, gracias a que contaron con una subvención total de los costes salariales (más de 1.700 euros mensuales por cada contrato de trabajo). De esos puestos, solo un 10,9 por cien $(612$ personas) ha mantenido su empleo al terminar los seis meses. Otro 15 por cien (842 personas) ha encontrado trabajo fuera del programa. Un 
programa carísimo, que ha sido reeditado para este año, y que solo sirve para maquillar temporalmente las cifras del desempleo, no se puede vender como el símbolo de la eficacia que se espera de LANBIDE como futuro dinamizador de la empleabilidad en Euskadi.

La coerción hacia la empleabilidad de la gente perceptora de la Renta de Garantía de Ingresos va a deparar para la patronal un enorme beneficio. Le va a poner a su disposición un ejército de reserva de gente parada o con trabajos precarios obligada a admitir cualquier tipo de empleo, en cualesquiera circunstancias, que le resultará muy favorable para abaratar el coste salarial y para generar división con el resto de las personas empleadas en condiciones más dignas.

c) Las campañas destinadas a seguir ensombreciendo el sistema de las ayudas sociales y a sus personas perceptoras con el tema del fraude, van a continuar. Tienen el terreno abonado en una opinión pública machacada por la crisis y que busca sus enemigos entre los colectivos más frágiles de la sociedad (personas inmigrantes, pobres, excluidos/as...) en lugar de fijarse en quienes detentan el poder del dinero y de la política. Estas campañas, a las cuales LANBIDE va a colaborar gustosamente, utilizando sus estadísticas (tenemos ejemplos recientes) para enredar y emborronar todo, haciendo aparecer como voluntad de no querer trabajar y otras modalidades de fraude, cosas que, en una mayoría de casos son meros problemas administrativos de la gente perceptora, siempre dejarán un rédito para quienes quieren ir socavando el sistema de ayudas sociales.

La realidad del fraude en las prestaciones sociales es insignificante. La propia administración reconocía, no hace mucho, que sus cifras no superaban el 4 por ciento del gasto en prestaciones. Para una previsión de gastos de 410 millones de euros en este epígrafe en 2011, supone 16.400 .000 euros, es decir el 0,16 por cien del Presupuesto del Gobierno vasco para este año. Basta compararlo con los 2.000.000.000 euros en que se estima el fraude fiscal

El rédito de las campañas contra el fraude es ya muy evidente: las prestaciones sociales de la comunidad autónoma del País Vasco, prestigiadas por una gran mayoría de la ciudadanía durante veinte años, han cosechando en los últimos tres o cuatro años, un notable desprestigio. Estas operaciones suelen ser la antesala para justificar mayores ataques a determinadas partidas de gastos sociales.

\section{Conclusiones}

De forma muy resumida, quiero plantear, para terminar, algunas de las principales ideas desarrolladas a lo largo de este artículo.

a) El modelo de rentas mínimas inaugurado en Euskadi a finales de los años 80 del siglo pasado ha jugado un papel importante en combatir la pobreza más extrema.

b) Su diseño, muy hipotecado a la filosofía del control de rentas y de la condicionalidad, no ha sido capaz de ir generando condiciones para dar el paso hacia un modelo distinto basado en la filosofía de la Renta Básica Universal o Ciudadana.

c) No ha existido un movimiento social de contestación y de propuesta de alternativas que haya tenido continuidad en el tiempo, como el desarrollado en la segunda mitad de los años 1990, capaz de confrontar con las administraciones a la hora de plantearse reformas de calado en el modelo de las rentas mínimas de la comunidad autónoma del País Vasco.

d) En los últimos cuatro años hemos entrado en una fase de retroceso del modelo. Aunque los elementos que lo han venido sosteniendo desde que fue implantado no han cambiado, en lo esencial, los recortes impuestos y la gestión de los mismos hará que el empeoramiento de condiciones para acceder a las prestaciones y la posibilidad de mantenerse en ellas, deje a miles de posibles perceptores y perceptoras fuera de estas prestaciones.

e) Es previsible que en Euskadi desandemos el camino de los últimos veinte años en cuanto a la mejora de la lucha contra la pobreza y que fruto de la ofensiva de recortes en las prestaciones sociales, unida a la nula efectividad que tendrá la política de empleabilidad en los años que aún tenemos de crisis por delante, nos encontremos con niveles de pobreza como los de los años 1986-1996. 


\section{Referencias bibliográficas}

AA.VV. (2009). 1984:2008. 25 años de estudio de la pobreza en Euskadi. Vitoria-Gasteiz: Servicio Central de Publicaciones del Gobierno Vasco.

Ezker Sindikalaren Konbergentzia (ESK) (noviembre 2002). Para seguir empujando hacia la consecución de una Renta Básica. GAIAK, 4.

Ley 2/1990, de 3 de mayo, del Ingreso Mínimo de Inserción.

Ley 12/1998, de 22 de mayo, contra la Exclusión Social.

Ley 10/2000, de 27 de diciembre, de Carta de Derechos Sociales.

Ley 18/2008, para la Garantía de Ingresos y la Inclusión Social.

Sanzo, Luis (noviembre, 2009). Vias para ajustar los programas de Rentas Mínimas a los principios de aplicación de la Renta Básica. IX Simposio de la Renta Básica. Bilbao.

Uribarri, Iñaki (noviembre, 2009). La experiencia de las Rentas Mínimas en la CAV. IX Simposio de la Renta Básica. Bilbao. 